\title{
Endoscopic ultrasound-directed transgastrojejunal ERCP: a new technique to treat biliary stricture through the afferent limb after Whipple surgery
}

Biliary drainage in patients with altered anatomy usually requires either percutaneous biliary drainage or endoscopic retrograde cholangiopancreatography (ERCP) performed with enteroscopy, so called e-enteroscopy [1]. In a meta-analysis, e-enteroscopy was successful in $70 \%$ of cases, with a mean procedure duration of $>80$ minutes [2]. Endoscopic ultrasound (EUS)-guided antegrade drainage using a previous EUS-guided hepaticogastrostomy is the most commonly performed EUS procedure in altered anatomy, with technical and clinical success rates ranging from $85 \%$ to $91.9 \%[3,4]$. In cases of bariatric gastric bypass, EUSdirected transgastric ERCP is a technique used to access the excluded stomach after Roux-en-Y- bariatric bypass through gastrogastrostomy with the duodenoscope [1].

A 73-year-old woman was referred with jaundice. She had undergone Whipple surgery for a tumor in the pancreatic head seven years ago. Pathological analysis showed a $5-\mathrm{cm}$ pancreatic neuroendocrine tumor, WHO grade 2, pT3NOMO, Ki-67 6\%. During follow-up, liver metastasis occurred with jaundice and pruritus. Magnetic resonance imaging at the last investigation showed invasion of the hilum of the liver with dilatation of biliary ducts in the right lobe and complete atrophy of the left lobe.

Management with EUS-guided hepaticogastrostomy was not possible and e-enterosocopy failed. To avoid percutaneous biliary drainage, we decided to access the afferent limb of the surgical hepaticojejunostomy by performing EUS-guided gastrojejunostomy (> Fig. 1, > Fig. 2 and - Fig. 3), then accessing the choledochojejunal surgical anastomosis (EUS-GJ) (\Fig.4). Under EUS guidance, an EUSguided gastrojejunal anastomosis was performed through the antrum wall with direct approach ( $\vee$ Video 1$)$. The postoperative course was uneventful.

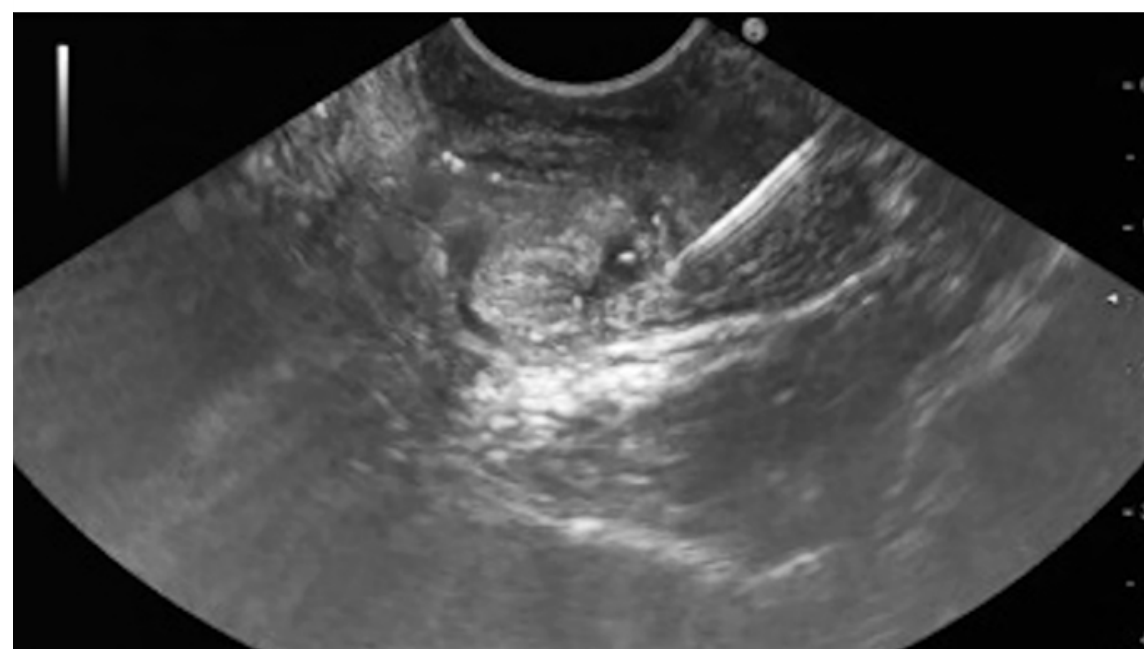

Fig. 1 Endoscopic ultrasound puncture of the afferent limb through the gastric wall.

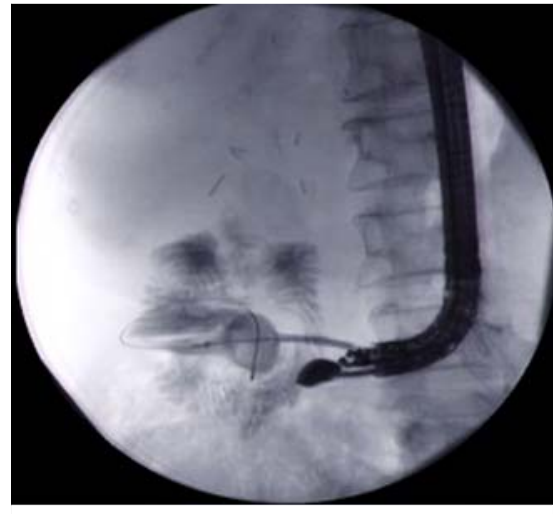

Fig. 2 X-ray view of the release of the distal flange.

Three weeks later, an ERCP was performed through the EUS-G] with a colonoscope easily reaching the choledochojejunal anastomosis (\$Fig.4). Biliary drainage was performed by inserting two plastic stents. The postoperative course was uneventful, with complete resolution of the jaundice.

Endoscopy_UCTN_Code_TTT_1AR_2AK

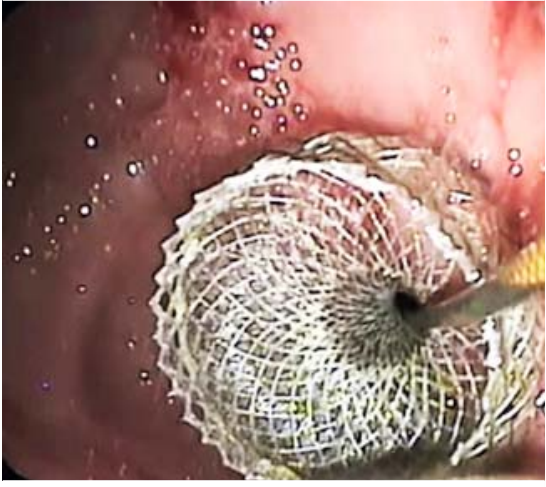

Fig. 3 Endoscopic view of the release of the proximal flange.

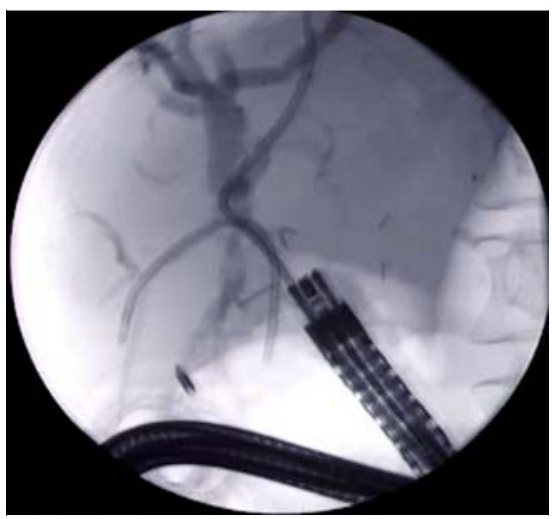

Fig. 4 Cholangiography with the axial scope. 


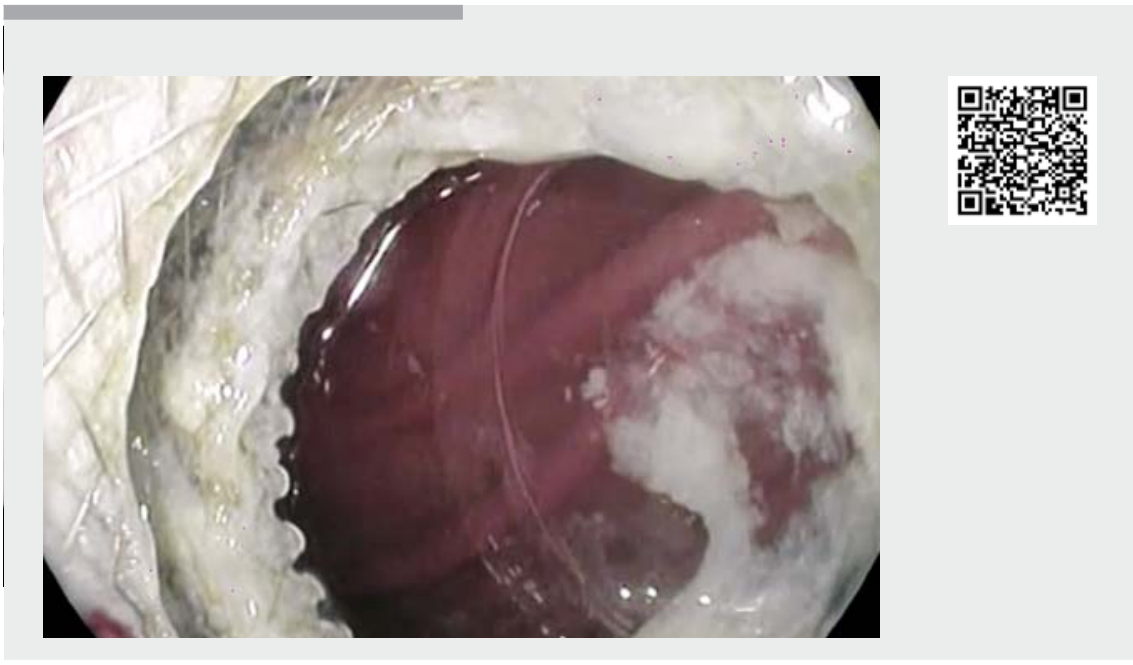

Video 1 Endoscopic ultrasound-guided gastrojejunostomy with the afferent limb, followed by endoscopic retrograde cholangiopancreatography through the gastrojejunostomy.

\section{Competing interests}

Professor Barthet and Dr. Gonzalez are consultants for Boston Scientific.

The authors

\section{Mohamed Gasmi, Jean-Michel Gonzalez, Marc} Barthet

Department of Hepatogastroenterology, Assistance Publique des Hôpitaux de Marseille, Aix-Marseille Université, Hôpital Nord, Marseille, France

[2] Skinner M, Popa D, Neumann H et al. ERCP with the overtube-assisted enteroscopy technique: a systematic review. Endoscopy 2014; 46: 560-572

[3] James TW, Fan C, Baron TH. EUS-guided hepaticoenterostomy as a portal to allow definitive antegrade treatment of benign biliary diseases in patient with surgically altered anatomy. Gastrointest Endosc 2018; 88: 547-554

[4] Mukai S, Itoi T, Sofuni A et al. Efficacy and safety of EUS-guided intervention for benign biliary disease with altered anatomy. Gastrointest Endosc 2019; 89: 397-407

\section{Bibliography}

Endoscopy 2020; 52: E441-E442

DOI 10.1055/a-1158-8559

ISSN 0013-726X

published online 12.5 .2020

(c) 2020. Thieme. All rights reserved.

Georg Thieme Verlag KG, Rüdigerstraße 14,

70469 Stuttgart, Germany

Corresponding author

\section{Marc Barthet, MD}

Department of Hepatogastroenterology, AP-HM, Aix-Marseille Université, Hôpital Nord, Chemin des Bourrely, 13015 Marseille, France

Fax: +33-4-91968737

marc.barthet@ap-hm.fr

\section{References}

[1] Bukhari M, Kowalski T, Nieto J et al. An international, multicenter, comparative trial of EUS-guided gastrostomy-assisted ERCP versus enteroscopy-assisted ERCP in patients with Roux-en-Y bypass anatomy. Gastrointest Endosc 2018; 88: 486-494

\section{ENDOSCOPY E-VIDEOS}

https://eref.thieme.de/e-videos

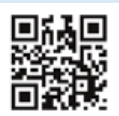

Endoscopy E-Videos is a free access online section, reporting on interesting cases and new techniques in gastroenterological endoscopy. All papers include a high quality video and all contributions are freely accessible online.

This section has its own submission website at

https://mc.manuscriptcentral.com/e-videos 